\title{
Export Production in the Equatorial and North Pacific Derived from Dissolved Oxygen, Nutrient and Carbon Data
}

\author{
REINER SCHLITZER* \\ Alfred Wegener Institute for Polar and Marine Research, Columbusstrasse, Bremerhaven, Germany
}

(Received 6 August 2003; in revised form 11 November 2003; accepted 14 November 2003)

\begin{abstract}
A global ocean inverse model that includes the 3D ocean circulation as well as the production, sinking and remineralization of biogenic particulate matter is used to estimate the carbon export flux in the Pacific, north of $10^{\circ} \mathrm{S}$. The model exploits the existing large datasets for hydrographic parameters, dissolved oxygen, nutrients and carbon, and determines optimal export production rates by fitting the model to the observed water column distributions by means of the "adjoint method". In the model, the observations can be explained satisfactorily with an integrated carbon export

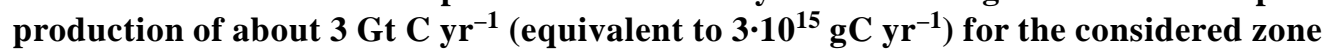
of the Pacific Ocean. This amounts to about a third of the global ocean carbon export of 9.6 Gt $\mathrm{C} \mathrm{yr}^{-1}$ in the model. The highest export fluxes occur in the coastal upwelling region off northwestern America and in the tropical eastern Pacific. Due to the large surface area, the open-ocean, oligotrophic region in the central North Pacific also

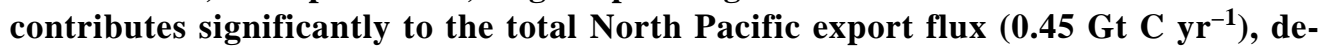
spite the rather small average flux densities in this region $\left(13 \mathrm{gC} \mathrm{m}^{-2} \mathrm{yr}^{-1}\right)$. Model $e$ ratios (calculated here as ratios of model export production to primary production, as inferred from satellite observations) range from as high a value as 0.4 in the tropical Pacific to 0.17 in the oligotrophic central north Pacific. Model $e$-ratios in the northeastern Pacific upwelling regions amount to about 0.3 and are lower than previous estimates.
\end{abstract}

Keywords:

- Export production,

- carbon cycle,

- modeling,

- nutrients,

- oxygen.

\section{Introduction}

Biological activity in the surface layer of the ocean leads to an uptake of dissolved nutrients and carbon from the sea-water and to the production of particulate and dissolved organic material. A fraction of the particulate matter obtained by primary production (PP) sinks into deeper layers, where it is remineralized, and nutrients and carbon are returned to the dissolved pool. This export flux of particulate matter out of the euphotic zone (export production, EP) acts as a downward material pump (Volk and Hoffert, 1985) that produces vertical nutrient and carbon gradients, with low concentrations in surface water and high values below. The decrease of surface water carbon concentrations affects surface water $p \mathrm{CO}_{2}$ values and ultimately controls the air-sea $\mathrm{CO}_{2}$ exchange and atmospheric $\mathrm{CO}_{2}$ concentrations.

\footnotetext{
* E-mail address: rschlitzer@awi-bremerhaven.de Copyright (c) The Oceanographic Society of Japan.
}

In order to sustain biological production in the sunlit upper layer of the ocean, a continuous supply of dissolved nutrients from below is required. This nutrient supply can be accomplished by upwelling of nutrient-rich thermocline or deeper water in Ekman divergent regions along coasts or near the equator and by deep-reaching winter convection and mixing. Eddy activity is also seen to supply nutrients to the euphotic zone, although the net effect of eddies on the magnitude of export fluxes is still a matter of debate (McGillicuddy et al., 1998, 2003; Oschlies, 2002). In the Pacific ocean, upwelling in equatorial and coastal regions as well as convection and vertical mixing processes in sub-polar and polar areas appear to be especially effective, as can be seen in the distribution of surface water phosphate shown in Fig. 1(a). The map is based on the historical data collection of Reid and Mantyla (available for download at http://www.awibremerhaven.de/GEO/ODV/data/Reid-Mantyla/ index.html) and bottle data from the World Ocean Circulation Experiment WOCE (available for download at http:/ /www.ewoce.org) and represents the annual average situ- 

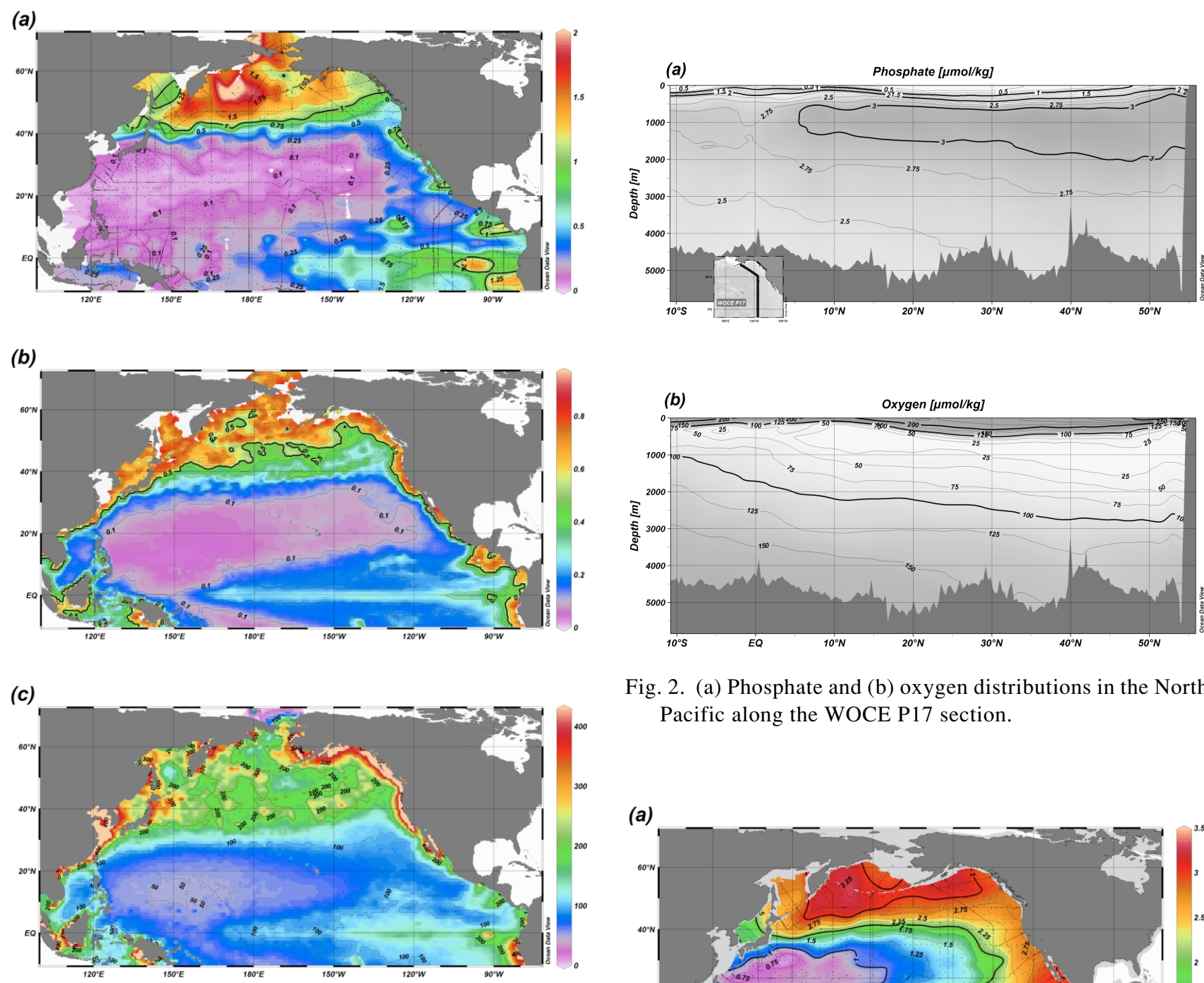

Fig. 2. (a) Phosphate and (b) oxygen distributions in the North Pacific along the WOCE P17 section.

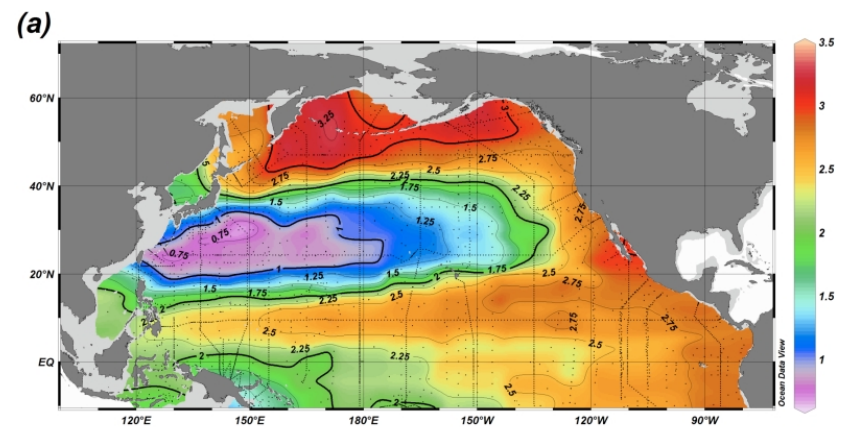

Fig. 1. (a) Annual average surface water $(30 \mathrm{~m}$ depth $)$ phosphate concentrations $\left[\mu \mathrm{mol} \mathrm{kg} \mathrm{kg}^{-1}\right]$ from historical hydrographic data, (b) annual average surface water chlorophyll a concentrations $\left[\mathrm{mg} \mathrm{m}^{-3}\right.$ ] for 1999 , from the SeaWiFS Project, (NASA/Goddard Space Flight Center and ORBIMAGE), and (c) annual average primary productivity $\left[\mathrm{gC} \mathrm{m}^{-2} \mathrm{yr}^{-1}\right]$ redrawn from Behrenfeld and Falkowski (1997).

ation with a slight bias towards the summer season, especially in polar regions.

The data show that phosphate levels are high over large areas in the tropical eastern Pacific, along the North American coast and in the entire North Pacific north of $40^{\circ} \mathrm{N}$, while in the center of the subtropical gyre in the western North Pacific, phosphate concentrations are very low and near detection limit (Fig. 1(a)). Chlorophyll a maps from satellite ocean color sensors (Fig. 1(b)) and maps of primary productivity derived from satellite data

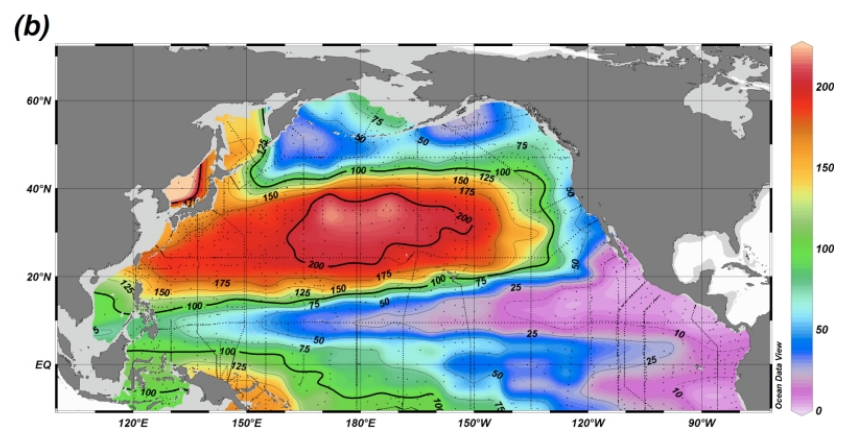

Fig. 3. (a) Phosphate and (b) oxygen distributions in $400 \mathrm{~m}$ depth from historical hydrographic data. Units are $[\mu \mathrm{mol}$ $\mathrm{kg}^{-1}$ ]. 
(Fig. 1(c)) show patterns of biological activity that closely match the pattern of surface nutrients, e.g., chlorophyll concentrations and productivity appear high in the tropical eastern Pacific, along the North American coast and north of $40^{\circ} \mathrm{N}$, whereas the subtropical gyre in the western Pacific stands out with little biological activity and production. Compared to other ocean basins, such as the North Atlantic, it appears that the North Pacific exhibits a higher surface nutrient availability and presumably higher biological productivity, making it an important region for global ocean nutrient and carbon cycle studies.

Because of the large potential impact on the atmospheric $\mathrm{CO}_{2}$ budget and global climate, determining the strength of the biological pump, e.g., the magnitudes of export production and downward particle fluxes, has been a high-priority research goal for a long time. Three main experimental approaches have been developed: (1) the direct measurement of the vertical particle fluxes with moored or drifting sediment traps (Honjo et al., 1982, 1995; Wefer et al., 1982; Kawahata et al., 2000), (2) the estimation of primary or export production from surfacewater chlorophyll concentrations obtained from satellites (Longhurst et al., 1995; Antoine et al., 1996; Behrenfeld and Falkowski, 1997; Arrigo et al., 1998; Laws et al., 2000), and (3) the determination of oxygen utilization rates in tracer-dated thermocline, intermediate and deep water masses (Jenkins, 1987; Emerson et al., 1997; Feely et al., 2004).

Here, a different approach is taken to estimate the export flux of particulate carbon and nutrients from the euphotic zone. The principle is based on Riley (1951), who suggested that the underlying biogeochemical processes could be determined and quantified from observed distributions of oxygen, nutrients, and carbon. As an example, Fig. 2 shows phosphate and oxygen distributions along a meridional section in the North Pacific (WOCE P17; data available at http://www.ewoce.org). Note the very low dissolved phosphate concentrations near the surface in the tropics and subtropics, which are the result of biological uptake. Also note that the nutrient depleted surface layer is very thin $(<100 \mathrm{~m})$, except in the center of the subtropical gyre (ca. $25^{\circ} \mathrm{N}$ ), where low-nutrient waters penetrate down to about $300 \mathrm{~m}$ depth due to Ekman pumping. At the northern end of the section, surface phosphate concentrations are much higher, but significant nutrient draw-down in the surface layer seems to occur in this area as well, as indicated by the large vertical phosphate gradient found north of about $45^{\circ} \mathrm{N}$ (Fig. 2(a)). Below the depleted surface layer, phosphate concentrations increase drastically with depth and reach maximum levels at about $1000 \mathrm{~m}$. These maxima in the phosphate vertical distribution are associated with strong oxygen minima (Fig. 2(b)), pointing to the remineralization of sinking particulate material as the cause for the high phosphate and low oxygen patches.

The geographical pattern of the particle remineralization signal is revealed by the phosphate and oxygen distributions in $400 \mathrm{~m}$ depth, shown in Fig. 3. High phosphate and low oxygen concentrations, indicating strong particle remineralization and high productivity in the surface layer above, are found in the tropical eastern Pacific, along the north American coast and in the open-ocean North Pacific north of $40^{\circ} \mathrm{N}$. These inferred areas of high biological activity match remarkably well with regions of high chlorophyll or primary productivity as obtained from satellite observations (Figs. 1(b) and (c)), and the two independent methods seem to yield consistent results. It should be noted that the phosphate and oxygen concentrations cannot be translated directly into productivity values or remineralization rates because mixing and water mass transports also play a role (see below).

It is important to note that the biogeochemically induced features in the nutrient, oxygen and carbon distributions have large amplitudes, and that these features are well resolved by the available data. The historical data used in this study span a large time period of more than 50 years, and the averaged dissolved property fields reflect the long-term mean effect of biological particle production and remineralization. Therefore, evaluation of the historical data will yield mean productivity and remineralization estimates over several decades and will not resolve temporal changes on seasonal and interannual time-scales as found in recent observations (Matear et al., 2000; Emerson et al., 2001; Ono et al., 2001). Long-term average ocean productivity estimates as provided by the present model study are needed as baseline values for global change studies and they are essential for global budget considerations. Large-scale and long-term mean productivity values are difficult to obtain from other approaches, such as satellite or sediment trap surveys.

Apart from the effect of biogeochemical processes on marine nutrient, carbon and oxygen fields, these distributions are also strongly affected by the mixing and water mass transport. A successful determination of biogeochemical flux rates from dissolved nutrient and oxygen fields therefore also requires to take physical processes into account. This is addressed by the inverse approach described below. In contrast to forward models that simulate tracer distributions on the basis of known flow fields and biogeochemical fluxes, here, the physical transports and biogeochemical rate constants are deduced from water-column concentration data. Since Riley's (1951) work, the amount and quality of available data has increased tremendously. In addition, advances in computer technology and numerical methods now allow detailed studies on a global scale that deal with many parti- 
cle species and a large variety of tracers simultaneously.

The model strategy described below employs the adjoint method to determine optimal flows (physics) and production as well as remineralization parameters (biogeochemistry), that explain the global hydrography and the measured concentration fields of dissolved nutrients, carbon and oxygen, best. The problem is formulated as a constrained optimization and the solution is found iteratively. It should be noted that in contrast to ecosystem models (Fasham et al., 1990; Moore et al., 2001) that attempt to describe the complicated interactions and feedbacks of biological food-webs and community structures explicitly, in the present case the processes leading to the production, export and subsequent remineralization of particles are not resolved by the model, but parameterized as source/sink rate constants to be determined by the model. The unknown production or remineralization rates are only constrained by the requirement to reproduce the observed property distributions realistically. As described below, empirical flux-depth relations are applied, but other biogeochemical a priori information about the underlying processes is not incorporated.

In this paper, carbon export production results from the inverse model are presented for the North Pacific. The model export fluxes are then compared with primary productivity maps based on satellite data and other productivity estimates. Model export efficiencies (e-ratios), defined as ratios between model export production and independent primary production estimates, are calculated and discussed in the context of results from the literature.

\section{Inverse Model}

As described above, determining particle fluxes and near-surface production rates from nutrient concentrations requires a biogeochemical model that also includes the ocean's 3-D circulation. Here, the global model of de las Heras and Schlitzer (1999) and Schlitzer (2000) is used that has already been fitted to global hydrographic, nutrient and oxygen fields. The general model strategy is based on Schlitzer (1993), and more details can be found there and in Schlitzer $(1995,1996,2000,2002)$. In the following, the model setup is briefly described and then the extensions with respect to biogeochemical cycles are explained.

Overall goal of the model calculations is to find a steady global ocean flow field (representing the climatological mean circulation) and mean export production of particulate organic carbon (POC) as well as POC fluxes throughout the water column and to the seafloor. To be considered optimal, the calculated velocities must have velocity shears that are close to geostrophic shear estimates and simulations of hydrographic and nutrient distributions must reproduce the respective obser- vations accurately (see Schlitzer (1993) for more details). The adjoint method provides the means that drive the model to the desired state (see Schlitzer (2000) for more details).

The model is of global extent and uses a non-uniform grid with horizontal resolution ranging from $5 \times 4$ degrees longitude by latitude in open ocean areas to $1 \times 1$ degrees in regions with narrow currents (Drake Passage, Atlantic part of the Antarctic Circumpolar Current, Indonesian and Caribbean archipelagos), along coastal boundaries with strong currents (Florida Current, Gulf Stream, Brazil Current, Agulhas Current, Kuroshio), over steep topography (Greenland-Iceland-Scotland overflow region) and in areas with pronounced coastal upwelling or downwelling. In all cases the refinements are implemented in the direction of the strongest property gradients (usually perpendicular to fronts and currents) to better trace changes in ocean properties.

The model has 26 vertical layers, with thickness progressively increasing from $60 \mathrm{~m}$ at the surface to approximately 500 meters at $5000 \mathrm{~m}$ depth. Realistic topography is used, based on the U.S. Navy bathymetric data and averaged over grid-cells. Model depths over ridges and in narrow channels are adjusted manually to respective sill or channel depths. The model has three open boundaries, along which ocean properties and transports are prescribed in each model layer. They are located at the exit of the Mediterranean Sea, Red Sea and Persian Gulf. These three marginal seas are not modeled explicitly, but their impact on the global circulation is taken into account.

Model tracer values are defined at the centers of the grid-boxes whereas flows are defined on the interfaces (Arakawa C-grid). Formation of particulate material is occurring in the top two model layers with the top layer contributing $75 \%$ and the second layer contributing $25 \%$ of the total production. The bottom of the second model layer is considered the base of the euphotic zone (here: $z_{E Z}=133 \mathrm{~m}$ ). Particle fluxes below the euphotic zone are assumed to decrease with depth according to

$$
j_{P}(z)=a \cdot\left(z / z_{E Z}\right)^{-b}
$$

This functional relationship is commonly used for the depth dependence of the flux of particulate organic carbon (POC) (Suess, 1980; Martin et al., 1987; Bishop, 1989). In Eq. (1) $a$ is the particle flux at the base of the euphotic zone, $z_{E Z}$, and represents the export production. The parameter $b$ determines the shape of particle flux profile below the euphotic zone and controls the depth of remineralization. Large values for $b$ correspond to steep particle flux decreases and thus large remineralization rates just below the euphotic zone, whereas values for $b$ close to zero result in almost constant particle fluxes in- 
dependent of depth, with little remineralization in the water column and most of the particle export reaching the ocean floor.

In the model, export production $a$ and remineralization scale height $b$ may vary from grid column to grid column. Note that these parameters are not formally dependent on environmental factors such as nutrient availability, light intensity or density stratification, as implemented in other biogeochemical models (Maier-Reimer, 1993; Yamanaka and Tajika, 1996), but can be freely chosen by the model to achieve optimal agreement with measured oxygen, nutrient and carbon fields.

The computational strategy is explained in detail in Schlitzer (2000) and Schlitzer (2002), here only a brief summary will be given. The horizontal model flow field is initialized using geostrophic velocities calculated from original hydrographic data. Following suggestions from the literature (Reid, 1986; Whitworth and Nowlin, 1987; Rintoul and Wunsch, 1991; Rintoul, 1991; Reid, 1997) the reference level for the geostrophic calculations varies geographically: $z_{r}=1500 \mathrm{~m}$ north of $25^{\circ} \mathrm{S} ; z_{r}=3800$ $\mathrm{m}$ south of $45^{\circ} \mathrm{S}$; linear transition between $25^{\circ} \mathrm{S}$ and $45^{\circ} \mathrm{S}$.

The initial export fluxes of POM $a$ are derived from the productivity map of Berger (1989), and the initial values of the remineralization parameters $b$ are set to 1 (Suess, 1980). Using this set of initial independent parameters, model vertical velocities as well as model fields for temperature, salinity, oxygen, phosphate, nitrate, total inorganic carbon and alkalinity (dependent parameters) are calculated by applying steady-state conservation equations for mass, heat, salt, oxygen, nutrients, carbon, and alkalinity, respectively. This step of calculating the vertical velocities and model property fields is commonly referred to as a simulation.

Once calculated, the simulated property distributions can be compared with measurements. Usually, this model/ data comparison is done subjectively, and attempts are made to correct potential causes for model/data misfits by modifying the velocity and biogeochemical parameters and then running new simulations. While this approach usually is successful for box-models with a limited number of parameters, for large 3D models like the present one, the manual adjustment of parameters is impractical and in most cases does not lead to desired improvements.

The so-called adjoint method (Hestenes, 1975; Thacker and Long, 1988; Schlitzer, 2000) is an alternative to manual parameter-tuning, and allows treatment of optimization problems with a large number of adjustable parameters, like the present one. Here the evaluation of model/data misfits is performed automatically by using a suitably formulated cost function (see Schlitzer 2000 for a detailed discussion of cost function terms). A twin-model of the simulation step (the adjoint model) "learns" from the structure in the misfits and modifies the independent parameters (flows and biogeochemical parameters) in a systematic way that guarantees a better model/data agreement in the next simulation. By running the forward/ adjoint steps repeatedly, the model is driven closer and closer to the observations. The calculations are terminated when the decrease of the cost function (improvement) per iteration is smaller than a pre-defined limit.

Because of the huge computational requirements of the optimization procedure described above, and because of a general lack of biogeochemical data that fully describe the seasonal cycle, the present model is formulated as a steady-state, annual-mean model. The optimized model flow field and particle flux patterns represent longterm means over the time periods covered by the data that are used by the model (ca. 1939-2002), and no attempt is made to resolve time-dependent and sporadic events, such as eddies or individual bloom events.

In the following, results are presented from a model run that considers cycling of semi-labile dissolved organic matter (Kirchman et al., 1991; Hansell and Carlson, 1998) and $\mathrm{N}_{2}$ fixation as well as denitrification as sources and sinks for nitrate, in addition to particle production and remineralization as described by (1). This experiment is fitted to global ocean temperature, salinity, oxygen, dissolved nutrient $\left(\mathrm{PO}_{4}, \mathrm{NO}_{3}, \mathrm{SiO}_{2}\right)$ and carbon data and is identical with experiment $\mathrm{C}$ from Schlitzer (2002).

Nitrogen fixation rates are specified using information on globally integrated fixation rates from the literature (Codispoti and Christensen, 1985; Gruber and Sarmiento, 1997). In the model, nitrogen fixation is evenly distributed over those surface areas, where dissolved nitrate is lower than $5 \mu \mathrm{mol} \mathrm{kg}$, which includes all oligotrophic areas in mid and low latitudes. Denitrification in the model exactly matches total nitrogen fixation and is equally divided into water-column and benthic denitrification. The benthic denitrification is set to be proportional to the POC flux to the seafloor, and watercolumn denitrification is evenly spread over all volumes in which dissolved oxygen is below $20 \mu \mathrm{mol} \mathrm{kg}^{-1}$. This places most of the denitrification in the Pacific and Indian Ocean at a depth between 100 and $800 \mathrm{~m}$, which is in agreement with observational evidence (Codispoti and Christensen, 1985; Codispoti et al., 1986; Howell et al., 1997).

The elemental composition $\mathrm{P}: \mathrm{N}: \mathrm{C}: \mathrm{O}$ of $\mathrm{POC}$ is assumed to be constant in space $(1: 16: 106:-175$; Takahashi et al., 1985; Boulahdid and Minster, 1989; Anderson and Sarmiento, 1994), and at each model grid-point the exported particulate material is completely remineralized in the underlying water column. Model experiments including accumulation of POC in the sediments (Schlitzer et al., 2003) and with spatially variable elemental composition of POC (Schneider et al., 2003) have been performed, but yield POC export fluxes very similar to the 
results presented below. The air-sea fluxes of oxygen and $\mathrm{CO}_{2}$ are treated as unknown parameters in the model. These fluxes may vary spatially, and their values are determined by the model such that the combination of advective and diffusive fluxes in the surface layer together with the respective gas-exchange rates yield realistic oxygen and carbon concentrations. There is no inherent parameterization with wind speed or partial pressure differences and no need for making assumptions on the degree of saturation in the surface water.

\section{Model Results}

\subsection{Phosphate and oxygen distributions}

Figure 4 shows the optimal model simulated phosphate and oxygen distributions along the WOCE P17 section in the North Pacific. A comparison with the observations in Fig. 2 shows that the model realistically reproduces the phosphate draw-down near the surface as well as the mid-depth phosphate maximum and oxygen minimum. Both, the meridional and vertical extent of these features as well as the amplitudes of the extrema are in very good agreement with the data. Integrated over the whole North Pacific north of $10^{\circ} \mathrm{S}$, the mean and rms deviations in the main remineralization zone between 300 and $1300 \mathrm{~m}$ depth amount to only $-0.008 \pm 0.15 \mu \mathrm{mol}$ $\mathrm{kg}^{-1}$ for phosphate, and $-1.4 \pm 15 \mu \mathrm{mol} \mathrm{kg}{ }^{-1}$ for oxygen, respectively. These misfits are more than one order of magnitude smaller than those obtained with other global biogeochemical models of comparable resolution (MaierReimer, 1993; Yamanaka and Tajika, 1997; Matear and Hirst, 1999).

\subsection{Carbon export production}

The carbon export production rates in the North $\mathrm{Pa}$ cific corresponding to the realistic phosphate and oxygen model simulations in Fig. 4 are shown in Fig. 5(a). Overall, the model requires high carbon export rates in the tropical eastern and western Pacific, in the coastal area off the North American coast and in the northwestern Pacific. The highest export fluxes are reached in the northeastern Pacific coastal upwelling region, where values exceed $100 \mathrm{gC} \mathrm{m}^{-2} \mathrm{yr}^{-1}$ locally. In the oligotrophic central North Pacific, carbon export rates are much smaller, and reach minimal values of 7 to $10 \mathrm{gC} \mathrm{m}^{-2} \mathrm{yr}^{-1}$ in the subtropical western Pacific at about $20^{\circ} \mathrm{N}$.

Following the general pattern of model export fluxes shown in Fig. 5(a), the North Pacific is subdivided into five sub domains: (I) northwestern Pacific, (II) northeastern Pacific, (III) central north Pacific, (IV) tropical western Pacific, and (V) tropical eastern Pacific. Integrated carbon exports as well as average fluxes are provided for these domains in Fig. 5(b). Note that the areas of the domains differ widely. In the model, the largest contribu-
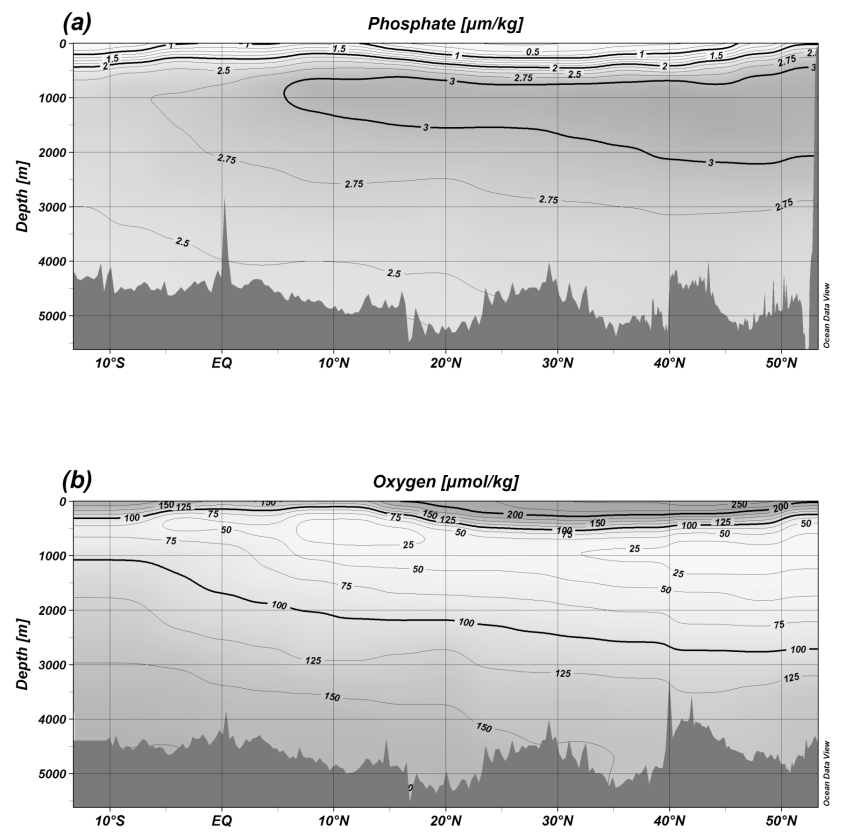

Fig. 4. Model simulated (a) phosphate and (b) oxygen distributions in the North Pacific along the WOCE P17 section.

tion to the carbon export in the North Pacific occurs in the tropical eastern Pacific (domain V), where the integral export amounts to about $1.3 \mathrm{Gt} \mathrm{C} \mathrm{yr}^{-1}$ and the mean flux density is about $38 \mathrm{gC} \mathrm{m}^{-2} \mathrm{yr}^{-1}$. The other domains I to IV contribute similar amounts to the carbon export ( 0.3

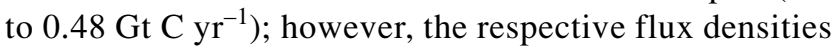
are very different and range between about $66 \mathrm{gC}$ $\mathrm{m}^{-2} \mathrm{yr}^{-1}$ in the northeastern Pacific upwelling area (II) and about $13 \mathrm{gC} \mathrm{m}^{-2} \mathrm{yr}^{-1}$ in the oligotrophic central Pacific (III). Summed over all domains, the model carbon export flux for the North Pacific north of $10^{\circ} \mathrm{S}$ is about $3 \mathrm{Gt} \mathrm{C}$ $\mathrm{yr}^{-1}$ and the mean flux density is $32 \mathrm{gC} \mathrm{m}^{-2} \mathrm{yr}^{-1}$.

Comparison with the surface phosphate distribution in Fig. 1(a) shows that carbon export in the model is closely linked to surface water dissolved nutrient content. In regions I, II and V, where high export fluxes are found (Fig. 5), surface phosphate concentrations are also high, and the extent of the nutrient rich patches corresponds closely to the regions with elevated export. Conversely, in the central North Pacific, where surface nutrient concentrations are very low (Fig. 1(a)), model export fluxes are also low, and, again, the extent of the nutrient depleted region closely corresponds to the low productivity area in the model.

A close correspondence between model productivity patterns and dissolved nutrients and oxygen is also found when comparing with the phosphate and oxygen distribution in $400 \mathrm{~m}$ depth shown in Fig. 3. Note that remineralization of sinking particulate material strongly 


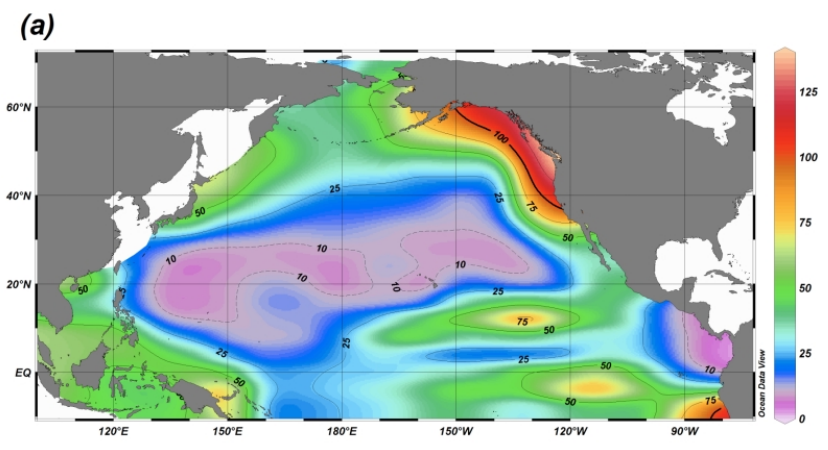

(b)

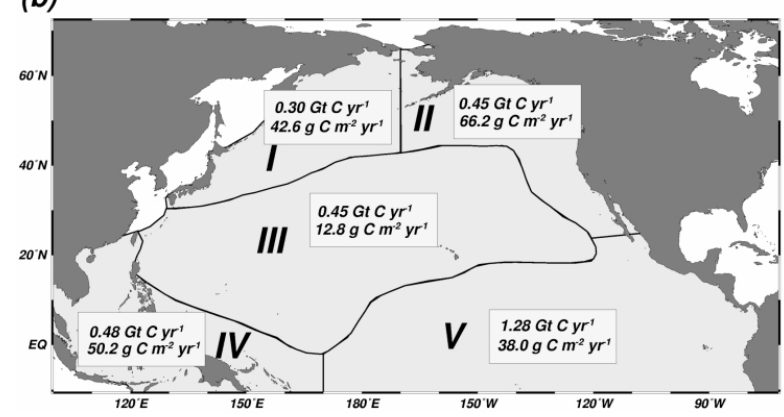

Fig. 5. (a) Model derived export production $\left[\mathrm{gC} \mathrm{m}^{-2} \mathrm{yr}^{-1}\right]$ in the North Pacific, and (b) regional integrals and mean flux values for five sub-domains.

affects mid-depth nutrient and oxygen distributions and a correlation between surface productivity and subsurface nutrient and oxygen fields is expected. It can be clearly seen that the two oxygen minima and phosphate maxima on both sides of the equator in the tropical eastern Pacific (Fig. 3(a)) correspond to the two productivity maxima in the same area (Fig. 5(a)). A good match between the remineralization signal in the dissolved tracer fields and the extend of the high productivity areas is evident also in the north Pacific north of $40^{\circ} \mathrm{N}$ and in the upwelling region off the North American coast. Physical processes, such as enhanced winter-time mixing and convection, can offset part of the remineralization signal, especially in mid and high latitudes, by replenishing oxygen to deeper thermocline layers and diluting nutrients by addition of depleted surface waters. Therefore, the relation between surface production and subsurface biogeochemical fields is nonlinear, and the existence of weaker oxygen minima in domains I and II with the highest export flux densities, as compared to the strong oxygen minima in the tropical eastern Pacific, is not surprising.

The basin-wide pattern of model export production in Fig. 5(a) is in good agreement with surface ocean chlorophyll as detected by satellite sensors and with primary productivity estimates based on the satellite data (Figs. 1(b) and (c)). As in the model results, the satellite derived maps show high biological activity in the tropical eastern and western Pacific, and in the entire Pacific Ocean north of $40^{\circ} \mathrm{N}$. This general agreement is remarkable because of the full independence of the methods used: whereas for the satellite maps the system is viewed from above and only signals from the very top layer of the ocean are exploited, the results of the inverse model fully depend on water column information from within and below the euphotic zone. In the eastern equatorial Pacific the spatial productivity pattern of the model is rather broad and closely corresponds with the sub-surface oxygen and nutrient distributions (see Fig. 3). The meridional extent of the model productivity patch roughly agrees with the high chlorophyll field as seen from satellites (Fig. 1(b)), however, there are significant small-scale differences that could be due to the limited spatial resolution of the model, to an underestimation of equatorial currents in the model and/or temporal variability in the chlorophyll fields.

\section{Discussion}

The model-derived integrated carbon export of $3 \mathrm{Gt}$ $\mathrm{C} \mathrm{yr}^{-1}$ for the Pacific Ocean north of $10^{\circ} \mathrm{S}$ is in good agreement with the carbon export estimates of Feely et al. (2004), based on apparent oxygen utilization data (AOU) and water mass ages from CFCs and natural radiocarbon measurements. Integrating their values for regions north of $3^{\circ} \mathrm{S}$ yields $2.4 \mathrm{Gt} \mathrm{C} \mathrm{yr}^{-1}$, which is almost identical with the model export of $2.3 \mathrm{Gt} \mathrm{C} \mathrm{yr}^{-1}$ calculated for the same domain. The model integral for the entire north and south Pacific ( $5 \mathrm{Gt} \mathrm{C} \mathrm{yr}^{-1}$ ) is somewhat higher than the $4.3 \mathrm{Gt}$

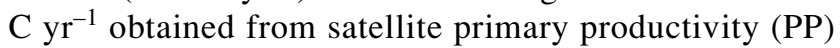
and the ef-ratios of Laws et al. (2000) but considerably smaller than the $8.3 \mathrm{Gt} \mathrm{C} \mathrm{yr}^{-1}$ derived from the same PP, but with $f$-ratios from Eppley and Peterson (1979).

In the oligotrophic north Pacific, model carbon export production estimates agree reasonably well with published values: (1) at station ALOHA $\left(22^{\circ} 45^{\prime} \mathrm{N}, 150^{\circ} \mathrm{W}\right)$, for which Emerson et al. (1997) obtain a POC export of $24 \pm 12$, the nearest model value amounts to $15 \mathrm{gC}$ $\mathrm{m}^{-2} \mathrm{yr}^{-1}$, (2) at VERTEX site $\mathrm{V}\left(28^{\circ} \mathrm{N}, 155^{\circ} \mathrm{W}\right)$, where Martin et al. (1987) measure $14 \mathrm{gC} \mathrm{m}^{-2} \mathrm{yr}^{-1}$, the model yields $10 \mathrm{gC} \mathrm{m}^{-2} \mathrm{yr}^{-1}$. Good agreement of model results with the VERTEX measurements is also found in the high productivity coastal upwelling region in the northeastern Pacific, where Martin et al. (1987) obtain $85 \mathrm{gC} \mathrm{m}^{-2} \mathrm{yr}^{-1}$ at site $\mathrm{I}\left(36.1^{\circ} \mathrm{N}, 122.6^{\circ} \mathrm{W}\right)$, and the model yields $112 \mathrm{gC}$ $\mathrm{m}^{-2} \mathrm{yr}^{-1}$. More recent ${ }^{234} \mathrm{Th}$ corrected POC flux estimates based on short-term observations in the northeastern Pacific (between $125^{\circ} \mathrm{W}$ and $145^{\circ} \mathrm{W}$ at $50^{\circ} \mathrm{N}$ ) (Charette et al., 1999), however, are much smaller than the respective model results (12-32 versus $\left.42-144 \mathrm{gC} \mathrm{m}^{-2} \mathrm{yr}^{-1}\right)$.

High model POC exports between 40 and $70 \mathrm{gC}$ 
$\mathrm{m}^{-2} \mathrm{yr}^{-1}$ are found in the western Pacific north of $30^{\circ} \mathrm{N}$ and in the Western Pacific Subarctic Gyre (WSG, ca. $\left.165^{\circ} \mathrm{E} / 50^{\circ} \mathrm{N}\right)$. These values agree well with independent new production estimates based on the seasonal nitrate drawdown determined from ship observations (Wong et al., 2002) or remotely sensed sea surface temperature (SST) and chlorophyll fields (Goes et al., 2000). The decrease of model POC exports in the open ocean northern Pacific to the east (values between 10 and $30 \mathrm{gC}$ $\mathrm{m}^{-2} \mathrm{yr}^{-1}$ ), is also in good qualitative and quantitative agreement with the results of Goes et al. (2000) and Wong et $a l$. (2002), and is also consistent with sediment trap measurements (Honda et al., 2002).

However, there is a marked disagreement in the northeastern Pacific, where the high POC exports of the inverse model (>100 gC m $\mathrm{g}^{-2} \mathrm{yr}^{-1}$; see Fig. 5(a)) are not seen in the productivity maps based on the seasonal nitrate drawdown. Contrary to the inverse model results, the POC export in the northeastern Pacific is small and of about the same magnitude as in the open ocean northern Pacific (about 20 to $40 \mathrm{gC} \mathrm{m}^{-2} \mathrm{yr}^{-1}$; Goes et al., 2000; Wong et al., 2002). It is argued here, that in the coastal region of the northeastern Pacific, where upwelling of nutrient-rich subsurface water is an important additional source of nutrients to the surface layer, the seasonal drawdown approach can underestimate productivity considerably and that these estimates are probably too low. While the nutrient supply by winter-time mixing is evident in and can be estimated from observations of seasonal nutrient changes, additional, time-independent inputs originating from, for instance, upwelling, lateral divergences, and other processes will not be evident in nutrient time series and their contribution to the local productivity will be missed. In support of the inverse model, high productivity in the coastal northeastern Pacific is also seen in satellite-derived productivity maps (Longhurst et al., 1995; Antoine et al., 1996; Behrenfeld and Falkowski, 1997) and in sediment trap measurements (Martin et al., 1987).

In the equatorial Pacific the relatively large POC export fluxes from the inverse model agree well with the estimates of Feely et al. (2004) based on oxygen utilization rates, and with the spatially integrated carbon export flux of Chavez and Barber (1987) (1 Gt C yr $\left.{ }^{-1}\right)$. Flux estimates based on sediment trap, radionuclide- and stable isotope measurements made during the U.S. Joint Global Ocean Flux Study (JGOFS) EqPac survey (Murray et al., 1997) and the French ORSTOM/FLUPAC program show a large scatter and range between about 10 and $70 \mathrm{gC}$ $\mathrm{m}^{-2} \mathrm{yr}^{-1}$ (Bacon et al., 1996; Murray et al., 1996, 1997; Rodier and Borgne, 1997; Zhang and Quay, 1997; Dunne et al., 2000; Le Borgne et al., 2002). The average value from these observations agrees well with the model export flux of $38 \mathrm{gC} \mathrm{m}^{-2} \mathrm{yr}^{-1}$.
Table 1. Average model export e-ratios $e_{\mathrm{M}}$, defined as ratios between model export production and the primary production shown in Fig. 1(c), for the five sub-domains outlined in Fig. 5(b). Also listed are ef values from Laws et al. (2000), and f-ratios $f_{\mathrm{E}}$ from the EP-PP relationship of Eppley and Peterson (1979) and the primary productivity estimates in Fig. 1(c).

\begin{tabular}{lccc}
\hline Region & $e_{\mathrm{M}}$ & $e f$ & $f_{\mathrm{E}}$ \\
\hline I & 0.20 & 0.35 & 0.42 \\
II & 0.30 & 0.32 & 0.41 \\
III & 0.17 & 0.18 & 0.24 \\
IV & 0.45 & 0.19 & 0.28 \\
V & 0.39 & 0.18 & 0.26 \\
\hline
\end{tabular}

Discrepancies between inverse model results and EqPac observations are seen when comparing e-ratios, defined as export/primary production (the satellite derived PP values in Fig. 1(c) are used as reference for model eratios). Whereas model e-ratios in the tropical eastern Pacific are as large as 0.39 (see Table 1; region V), ${ }^{234} \mathrm{Th}$ (Buesseler, 1998) or ${ }^{15} \mathrm{~N}$ (Aufdenkampe et al., 2001) normalized results only range between 0.04 and 0.20 . Integrated ef values of Laws et al. (2000) for the tropical eastern Pacific are also small and amount to only one half of the inverse model value. In the oligotrophic central $\mathrm{Pa}$ cific (domain III), integrated model e-ratios amount to about 0.17 and agree reasonably well with results from Laws et al. (2000) and Eppley and Peterson (1979) (0.18 and 0.24 , respectively). In the high productive north and northeastern Pacific (domains I and II). the model e-ratios are systematically lower than Laws et al. (2000) and Eppley and Peterson (1979) estimates (0.2-0.3 versus $0.32-0.42$ ).

\section{Acknowledgements}

I thank E. Laws, S. Emerson and M. Behrenfeld for stimulating discussions and for sharing numerical algorithms and data. Constructive comments from two anonymous reviewers helped to improve the manuscript and are gratefully acknowledged.

\section{References}

Anderson, L. A. and J. Sarmiento (1994): Redfield ratios of remineralization determined by nutrient data analysis. Global Biogeochem. Cycles, 8, 65-80.

Antoine, D., J.-M. Andre and A. Morel (1996): Oceanic primary production 2. Estimation at global scale from satellite (coastal zone color scanner) chlorophyll. Global Biogeochem. Cycless, 10(1), 57-69.

Arrigo, K. R., D. Worthen, A. Schnell and M. P. Lizotte (1998): Primary production in Southern Ocean waters. J. Geophys. Res., 103, 15587-15600.

Aufdenkampe, A. K., J. J. McCarthy, M. Rodier, C. Navarette, 
J. Dunne and J. W. Murray (2001): Estimation of new production in the tropical Pacific. Global Biogeochem. Cycles, 15(1), 101-112.

Bacon, M. P., J. K. Cochran, D. Hirschberg, T. R. Hammar and A. P. Fleer (1996): Export flux of carbon at the equator during the EqPac time-series cruises estimated from ${ }^{234} \mathrm{Th}$ measurements. Deep-Sea Res. II, 43(4-6), 1133-1153.

Behrenfeld, M. J. and P. G. Falkowski (1997): Photosynthetic rates derived from satellite-based chlorophyll concentration. Limnol. Oceanogr., 42, 1-20.

Berger, W. H. (1989): Appendix. Global maps of ocean productivity. p. 429-455. In Productivity of the Ocean: Present and Past, ed. by W. H. Berger, V. S. Smetacek and G. Wefer, John Wiley \& Sons, Inc., New York.

Bishop, J. K. B. (1989): Regional extremes in particular matter composition and flux: effects on the chemistry of the ocean interior. p. 117-137. In Productivity of the Ocean: Present and Past, ed. by W. H. Berger, V. S. Smetacek and G. Wefer, John Wiley \& Sons, Inc., Chichester.

Boulahdid, M. and J. F. Minster (1989): Oxygen consumption and nutrient regeneration ratios along isopycnal horizons in the Pacific Ocean. Mar. Chem., 26, 133-153.

Buesseler, K. O. (1998): The decoupling of production and particulate export in the surface ocean. Global Biogeochem. Cycles, 12(2), 297-310.

Charette, M. A., S. B. Moran and J. K. B. Bishop (1999): ${ }^{234}$ Th as a tracer of particulate organic carbon export in the subarctic northeast Pacific Ocean. Deep-Sea Res. II, 46(1112), 2833-2861.

Chavez, F. P. and R. Barber (1987): An estimate of new production in the equatorial Pacific. Deep-Sea Res., 34(7), 1229-1243.

Codispoti, L.A. and J. P. Christensen (1985): Nitrification, denitrification and nitrous oxide cycling in the eastern tropical south Pacific Ocean. Mar. Chem., 16, 277-300.

Codispoti, L. A., G. E. Friederich, T. T. Packard, H. E. Glover, P. J. Kelly, R. W. Spinrad, R. T. Barber, J. W. Elkins, B. B. Ward, F. Lipschultz and N. Lostaunau (1986): High nitrite levels off nothern Peru: a signal of instability in the marine denitrification rate. Science, 233, 1200-1202.

de las Heras, M. and R. Schlitzer (1999): On the importance of intermediate water flows for the global ocean overturning. J. Geophys. Res., 104, 15515-15536.

Dunne, J. P., J. W. Murray, M. Rodier and D. A. Hansell (2000): Export flux in the western and central equatorial Pacific: zonal and temporal variability. Deep-Sea Res. I, 4 (5), 901936.

Emerson, S., P. Quay, D. Karl, C. Winn, L. Tupas and M. Landry (1997): Experimental determination of the organic carbon flux from open-ocean surface waters. Nature, 389, 951-954.

Emerson, S., S. Mecking and J. Abell (2001): The biological pump in the subtropical North Pacific Ocean: Nutrient sources, Redfield ratios, and recent changes. Global Biogeochem. Cycles, 15(3), 535-554.

Eppley, R. W. and B. J. Peterson (1979): Particulate organic matter flux and planktonic new production in the deep ocean. Nature, 282, 677-680.

Fasham, M. J. R., H. W. Ducklow and S. M. McKelvie (1990): A nitrogen-based model of plankton dynamics in the oceanic mixed layer. J. Mar. Res., 48, 591-639.
Feely, R. A., C. L. Sabine, R. Schlitzer, J. L. Bullister, S. Mecking and D. Greeley (2004): Oxygen utilization and organic carbon remineralization in the upper water column of the Pacific Ocean. J. Oceanogr., 60, this issue, 45-52.

Goes, J. I., T. Saino, H. Oaku, J. Ishizaka, C. S. Wong and Y. Nojiri (2000): Basin scale estimates of sea surface nitrate and new production from remotely sensed sea surface temperature and chlorophyll. Geophys. Res. Lett., 27(9), 12631266.

Gruber, N. and J. L. Sarmiento (1997): Global patterns of marine nitrogen fixation and denitrification. Global Biogeochem. Cycles, 11, 235-266.

Hansell, D. A. and C. A. Carlson (1998): Net community production of dissolved organic carbon. Global Biogeochem. Cycles, 12, 443-453.

Hestenes, M. R. (1975): Optimization Theory. John Wiley \& Sons, Inc., New York.

Honda, M. C., K. Imai, Y. Nojiri, F. Hoshi, T. Sugawara and M. Kusakabe (2002): The biological pump in the northwestern North Pacific based on fluxes and major components of particulate matter obtained by sediment-trap experiments (1997-2000). Deep-Sea Res. II, 49(24-25), 5595-5625.

Honjo, S., S. J. Manganini and J. J. Cole (1982): Sedimentation of biogenic matter in the deep ocean. Deep-Sea Res., 29, 609-625.

Honjo, S., J. Dymond, R. Collier and S. J. Manganini (1995): Export production of particles to the interior of the equatorial Pacific Ocean during the 1992 EqPac experiment. DeepSea Res. II, 42(2-3), 831-870.

Howell, E. A., S. C. Doney, R. A. Fine and D. B. Olson (1997): Geochemical estimates of denitrification in the Arabian Sea and the Bay of Bengal during WOCE. Geophys. Res. Lett., 24, 2549-2552.

Jenkins, W. J. (1987): ${ }^{3} \mathrm{H}$ and ${ }^{3} \mathrm{He}$ in the Beta triangle: Observations of gyre ventilation and oxygen utilization rates. $J$. Phys. Oceanogr., 17, 763-783.

Kawahata, H., A. Suzuki and H. Ohta (2000): Export fluxes in the Western Pacific Warm Pool. Deep-Sea Res. I, 47(11), 2061-2091.

Kirchman, D. L., Y. Suzuki, C. Garside and H. W. Ducklow (1991): High turnover rates of dissolved organic carbon during a spring phytoplankton bloom. Nature, 352, 612614.

Laws, E. A., P. G. Falkowski, W. O. Smith, H. Ducklow and J. J. McCarthy (2000): Temperature effects on export production in the open ocean. Global Biogeochem. Cycles, 14, 1231-1246.

Le Borgne, R., R. A. Feely and D. J. Mackey (2002): Carbon fluxes in the equatorial Pacific: a synthesis of the JGOFS programme. Deep-Sea Res. II, 49(13-14), 2425-2442.

Longhurst, A., S. Sathyendranath, T. Platt and C. Caverhill (1995): An estimate of global primary production in the ocean from satellite radiometer data. J. Plankton Res., 17, 1245-1271.

Maier-Reimer, E. (1993): Geochemical cycles in an ocean general circulation model. preindustrial tracer distributions. Global Biogeochem. Cycles, 7, 645-677.

Martin, J. H., G. A. Knauer, D. M. Karl and W. W. Broenkow (1987): VERTEX: Carbon cycling in the northeast Pacific. Deep-Sea Res., 34, 267-285. 
Matear, R. J. and A. C. Hirst (1999): Climate change feedback on the future oceanic $\mathrm{CO}_{2}$ uptake. Tellus, B51(3), 722-733.

Matear, R. J., A. C. Hirst and B. I. McNeil (2000): Changes in dissolved oxygen in the Southern Ocean with climate change. Geochemistry Geophysics Geosystems, 1 , 2000GC000086.

McGillicuddy, D. J., A. R. Robinson, D. A. Siegel, H. W. Jannasch, R. Johnson, T. D. Dickey, J. McNeil, A. F. Michaels and A. H. Knap (1998): Influence of mesoscale eddies on new production in the Sargasso Sea. Nature, 394, 263-266.

McGillicuddy, D. J., L. A. Anderson, S. C. Doney and M. E. Maltrud (2003): Eddy-driven sources and sinks of nutrients in the upper ocean: Results from a $0.1^{\circ}$ resolution model of the North Atlantic. Global Biogeochem. Cycles, 17(2), 10.1029/2002GB001987.

Moore, J. K., S. C. Doney, J. A. Kleypas, D. M. Glover and I. Y. Fung (2001): An intermediate complexity marine ecosystem model for the global domain. Deep-Sea Res. II, 49(13), 403-462.

Murray, J. W., J. Young, J. Newton, J. Dunne, T. Chapin, B. Paul and J. J. McCarthy (1996): Export flux of particulate organic carbon from the central equatorial Pacific determined using a combined drifting trap- ${ }^{234} \mathrm{Th}$ approach. DeepSea Res. II, 43(4-6), 1095-1132.

Murray, J. W., R. Leborgne and Y. Dandonneau (1997): JGOFS studies in the equatorial Pacific. Deep-Sea Res. II, 44(910), 1759-1763.

Ono, T., T. Midorikawa, Y. W. Watanabe, K. Tadokoro and T. Saino (2001): Temporal increases of phosphate and apparent oxygen utilization in the subsurface waters of western subarctic Pacific from 1968 to 1998. Geophys. Res. Lett., 28(17), 3285-3288.

Oschlies, A. (2002): Can eddies make ocean deserts bloom? Global Biogeochem. Cycles, 10.1029/2001GB001830.

Reid, J. L. (1986): On the total geostrophic circulation of the South Pacific Ocean: flow patterns, tracers, and transports. Prog. Oceanogr., 16, 1-61.

Reid, J. L. (1997): On the total geostrophic circulation of the Pacific Ocean: flow patterns, tracers, and transports. Prog. Oceanogr, 39, 263-352.

Riley, G. A. (1951): Oxygen, phosphate, and nitrate in the Atlantic Ocean. Bull. Bingham Oceanogr. Coll., 13(1), 1-124.

Rintoul, S. R. (1991): South Atlantic interbasin exchange. $J$. Geophys. Res., 96, 2675-2692.

Rintoul, S. and C. Wunsch (1991): Mass, heat, oxygen and nutrient fluxes and budgets in the north Atlantic Ocean. DeepSea Res., 38 (Suppl.), S355-S377.

Rodier, M. and R. L. Borgne (1997): Export flux of particles at the equator in the western and central Pacific ocean. DeepSea Res. II, 44, 2085-2113.

Schlitzer, R. (1993): Determining the mean, large-scale circulation of the Atlantic with the adjoint method. J. Phys. Oceanogr., 23, 1935-1952.

Schlitzer, R. (1995): An adjoint model for the determination of the mean oceanic circulation, air-sea fluxes and mixing coefficients. Alfred-Wegener-Institut, Bremerhaven.

Schlitzer, R. (1996): Mass and heat transports in the South Atlantic derived from historical hydrographic data. p. 305323. In The South Atlantic: Present and Past Circulation, ed. by G. Siedler, G. Wefer, W. H. Berger and D. Webb, Springer, Berlin.

Schlitzer, R. (2000): Applying the adjoint method for global biogeochemical modeling. p. 107-124. In Inverse Methods in Global Biogeochemical Cycles, ed. by P. Kasibhatla, M. Heimann, D. Hartley, N. Mahowald, R. Prinn and P. Rayner, AGU Geophys. Monograph Series, Vol. 114.

Schlitzer, R. (2002): Carbon export fluxes in the Southern Ocean: results from inverse modeling and comparison with satellite based estimates. Deep-Sea Res. II, 49, 1623-1644.

Schlitzer, R., R. Usbeck and G. Fischer (2003): Inverse modeling of particulate organic carbon fluxes in the South Atlantic. In The South Atlantic in the Late QuaternaryReconstruction of Material Budget and Current Systems, ed. by G. Wefer, S. Mulitza and V. Rathmeyer, Springer, Berlin (in print).

Schneider, B., R. Schlitzer, G. Fischer and E.-M. Nöthig (2003): Depth-dependent elemental compositions of particulate organic matter (POM) in the ocean. Global Biogeochem. Cycles, 17(2), 1029/2002GB001871.

Suess, E. (1980): Particulate organic carbon flux in the oceanssurface productivity and oxygen utilization. Nature, $\mathbf{2 8 8}$, 260-263.

Takahashi, T., W. S. Broecker and S. Langer (1985): Redfield ratio based on chemical data from isopycnal surfaces. $J$. Geophys. Res., 90, 6907-6924.

Thacker, W. C. and R. B. Long (1988): Fitting dynamics to data. J. Geophys. Res., 93, 1227-1240.

Volk, T. and M. I. Hoffert (1985): Ocean carbon pumps: analysis of relative strengths and efficiencies in ocean-driven atmospheric $\mathrm{CO}_{2}$ changes. p. 99-110. In The Carbon Cycle and Atmospheric $\mathrm{CO}_{2}$ : Natural Variations Archean to Present, ed. by E. T. Sundquist and W. S. Broecker, AGU Geophysical Monograph 32, Washington, D.C.

Wefer, G., E. Suess, W. Balzer, G. Liebezeit, P. J. Müller, C. A. Ungerer and W. Zenk (1982): Fluxes of biogenic components from sediment trap deployment in circumpolar waters of the Drake Passage. Nature, 299, 145-147.

Whitworth, T., III and W. D. Nowlin, Jr. (1987): Water masses and currents of the southern ocean at the Greenwich meridian. J. Geophys. Res., 92, 6462-6476.

Wong, C. S., N. A. D. Waser, Y. Nojiri, F. A. Whitney, J. S. Page and J. Zeng (2002): Seasonal cycles of nutrients and dissolved inorganic carbon at high and mid latitudes in the North Pacific Ocean during the Skaugran cruises: determination of new production and nutrient uptake ratios. DeepSea Res. II, 49(24-25), 5317-5338.

Yamanaka, Y. and E. Tajika (1996): The role of the vertical fluxes of particulate organic matter and calcite in the oceanic carbon cycle: studies using an ocean biogeochemical general circulation model. Global Biogeochem. Cycles, 10, 361-382.

Yamanaka, Y. and E. Tajika (1997): Role of dissolved organic matter in the marine biogeochemical cycle: studies using an ocean biogeochemical general circulation model. Global Biogeochem. Cycles, 11, 599-612.

Zhang, J. and P. D. Quay (1997): The total organic carbon export rate based on ${ }^{13} \mathrm{C}$ and ${ }^{12} \mathrm{C}$ of DIC budgets in the equatorial Pacific region. Deep-Sea Res. II, 44(9-10), 21632190. 